\title{
Effect of Raw Material Characteristics on the Carbothermal Reduction of Titanium Dioxide
}

\author{
Gil-Geun Lee ${ }^{1}$ and Byoung-Kee Kim ${ }^{2}$ \\ ${ }^{1}$ Division of Materials Science \& Engineering, Pukyong National University, Yongdang-dong, Nam-gu, Busan 608-739, Korea \\ ${ }^{2}$ Korea Institute of Machinery \& Materials, Sangnam-dong, Changwon, Kyungnam 641-010, Korea
}

\begin{abstract}
In the present study, the focus is on the effect of the particle characteristics of titanium dioxide powder in the carbothermal reduction of the titanium dioxide/carbon system. Four types of titanium dioxide powders with various phase structures and mean particle sizes were mixed with carbon black. These mixtures were heat treated under a flowing argon atmosphere. The changes in the phase structure and thermal gravity of the mixtures during heat treatment were analyzed using XRD and TG-DTA. Titanium dioxide powders with 100\% anatase phase structure exhibit a higher titanium carbide (TiC) formation ability than the titanium dioxide powders with the mixed phase structure of the anatase and rutile phase structures. It was concluded that the phase structure of the titanium dioxide plays a more important role than the particle size on the carbothermal reduction of the titanium dioxide/carbon system.
\end{abstract}

(Received April 18, 2003; Accepted August 13, 2003)

Keywords: titanium dioxide, titanium carbide, carbothermal reduction, phase structure, particle size, powder

\section{Introduction}

Tool materials were generally composed of hard materials such as WC, TiC, TaC, TiCN and others, and soft binder materials such as $\mathrm{Co}$ and $\mathrm{Ni}^{1}{ }^{1)}$ Among the rest of those hard materials, titanium carbide (TiC) has a high melting point $(3533 \mathrm{~K})$, Young's modulus $(450 \mathrm{GPa})$ and hardness (Vickers; $29 \mathrm{GPa})$ with a low density $\left(4.93 \times 10^{3} \mathrm{~kg} / \mathrm{m}^{-3}\right)$. It also exhibits a high resistance to both oxidation and corrosion. ${ }^{2)}$ Therefore, titanium carbide is extensively used for cutting tools, grinding wheels, coating cutting tips and coating steel press tools, in the powder form.

The tool materials manufactured by the powder metallurgy process have a composite microstructure of hard particles dispersed in a soft binder matrix. The mechanical properties of the tool materials depend not only on the constituent materials but also on their microstructure. ${ }^{3)}$ The hardness, fracture toughness and wear properties of the tool materials were strongly influenced by the size of the hard particles and the distance of the mean free path among the hard particles at the same constitution composition. These mechanical properties increased simultaneously with decreasing particle size and the distance of the mean free path. To manufacture highperformance tool material with an ultrafine microstructure by the powder metallurgy process, raw powder materials with an ultrafine particle size should be used.

A number of processes exist for synthesizing titanium carbide powders, such as carbothermal reduction of titanium dioxide, ${ }^{4)}$ direct carbarization of titanium, ${ }^{5)}$ chemical reaction of titanium chloride $\left(\mathrm{TiCl}_{4}\right),{ }^{6)}$ self-propagating hightemperature synthesis, ${ }^{7)}$ amongst others. Each method has varying characteristics of particle size and distribution, morphology, state of agglomeration, chemical purity, and stoichiometry. The titanium carbide powder is commercially produced primarily by the carbothermal reduction of titanium dioxide by carbon, especially carbon black, over a temperature range of $1700 \sim 2100 \mathrm{~K}^{4)}$ The reaction behavior of the titanium dioxide/carbon mixture, especially titanium carbide formation, in the carbothermal reduction method is very important to obtain an optimized titanium carbide powder. The manufacturing of the ultrafine titanium carbide powder with a nonagglomerated state by this method should be known to be the reaction mechanism. The chemical mechanism of this reaction is often unknown, however, this is highly dependent on the conditions of the process parameters such as atmosphere, pressure and temperature. ${ }^{8,9)}$ It has been recently verified that the carbon particle (grain) size, the homogeneity of the titanium dioxide/carbon mixture and the ventilation of the powder's bed are important parameters for a low-temperature reaction. ${ }^{10,11)}$ However, the parameters related to the particle characteristics of the starting material of the titanium dioxide, such as the particle (grain) size and phase structure, have been rarely studied exhaustively. In the present study, the focus is on their role in the carbothermal reaction of the titanium dioxide/carbon system.

\section{Experimental Procedure}

The four kinds of starting titanium dioxide powders $\left(\mathrm{TiO}_{2}\right)$ used have different characteristics. They are reported in Table 1, which gives, in particular, the mean particle

Table 1 Characteristics of the starting titanium dioxide powders.

\begin{tabular}{|c|c|c|c|c|}
\hline & Variety & $\begin{array}{l}\text { Mean diameter } \\
\qquad(\mathrm{nm})\end{array}$ & $\begin{array}{c}\text { Crystalline size } \\
(\mathrm{nm})\end{array}$ & Supplier \\
\hline $\mathrm{TiO}_{2}(\mathrm{I})$ & $\begin{array}{c}95 \% \text { rutile } \\
+5 \% \text { anatase }\end{array}$ & 700 & $\begin{array}{c}\text { Rutile:66 } \\
\text { Anatase:70 }\end{array}$ & $\begin{array}{c}\text { Japan High } \\
\text { Purity } \\
\text { Chemical }\end{array}$ \\
\hline $\mathrm{TiO}_{2}(\mathrm{II})$ & $\begin{array}{c}15 \% \text { rutile } \\
+85 \% \text { anatase }\end{array}$ & 45 & $\begin{array}{c}\text { Rutile:22 } \\
\text { Anatase:20 }\end{array}$ & Daeggusa \\
\hline $\mathrm{TiO}_{2}(\mathrm{III})$ & $100 \%$ anatase & 30 & 16 & $\begin{array}{c}\text { Nanotech } \\
\text { Japan High }\end{array}$ \\
\hline $\mathrm{TiO}_{2}(\mathrm{IV})$ & $100 \%$ anatase & 300 & 47 & $\begin{array}{c}\text { Purity } \\
\text { Chemical }\end{array}$ \\
\hline
\end{tabular}



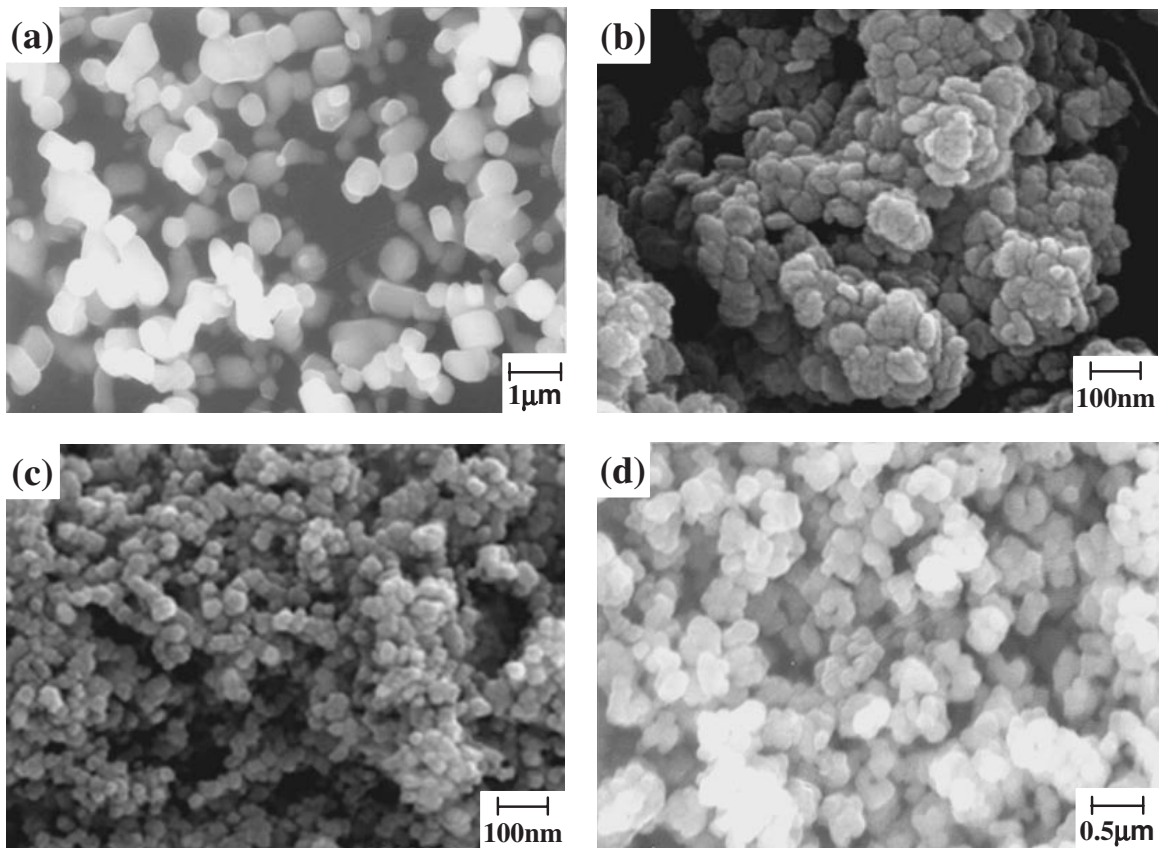

Fig. 1 SEM micrographs of (a) $\mathrm{TiO}_{2}$ (I), (b) $\mathrm{TiO}_{2}$ (II), (c) $\mathrm{TiO}_{2}$ (III) and (d) $\mathrm{TiO}_{2}$ (IV).

diameter measured by microscopy, the phase structure and the crystalline size measured by X-ray powder diffractometry with $\mathrm{Cu}-\mathrm{K} \alpha$ radiation, and the supplier. Figure 1 shows that their morphologies are very similar to each other. The $\mathrm{TiO}_{2}(\mathrm{I})$ powder has an almost stable rutile phase structure (about $95 \%$ rutile $+5 \%$ anatase) with the largest particle size, and the $\mathrm{TiO}_{2}$ (II) powder has an almost metastable anatase phase structure (about 15\% rutile $+85 \%$ anatase) with a nanoscale particle size. The $\mathrm{TiO}_{2}(\mathrm{III})$ and $\mathrm{TiO}_{2}(\mathrm{IV})$ powders have a $100 \%$ anatase phase structure, but these powders show different particle sizes. These four types of titanium dioxide powders are each mixed with carbon black (mean particle size: $0.5 \mu \mathrm{m}$ ) using an agate mortar. The quantities of titanium dioxide and carbon black were those of the reaction:

$$
\mathrm{TiO}_{2}+3 \mathrm{C} \rightarrow \mathrm{TiC}+2 \mathrm{CO}
$$

The mixtures were placed in a graphite crucible and then heat treated at a temperature from 1173 to $1472 \mathrm{~K}$ for 30 minutes in a tube furnace under a flowing stream of argon atmosphere. The weight of sample is $3 \mathrm{~g}$ for the heat treatment. After heat treatment, the samples were observed with a SEM and analyzed by X-ray diffraction. The changes in the thermal gravity of these powder mixtures during heat treatment from room temperature to $1673 \mathrm{~K}$ under a flowing stream of argon atmosphere were analyzed by TG-DTA with a heating rate of $5 \mathrm{~K} / \mathrm{min}$.

\section{Results and Discussion}

Figure 2 shows the change in the mass fraction of the mixture of titanium dioxide and carbon black with the temperature during carbothermal reduction under a flowing stream of argon atmosphere for the various types of the starting titanium dioxide powder. After weighting, the mass fraction was obtained by the ratio of the mass loss $(\Delta m)$ to its

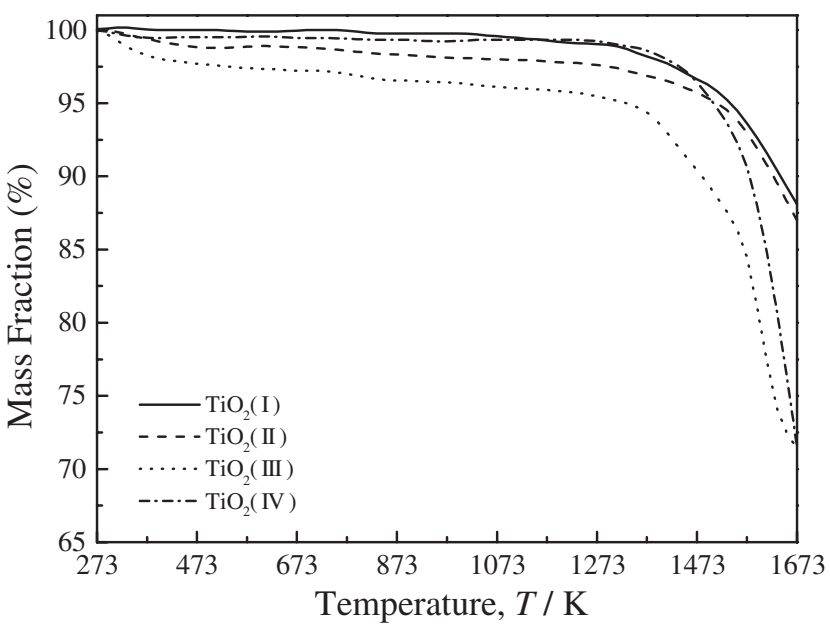

Fig. 2 Change in the mass fraction of the mixtures of titanium dioxide and carbon black with temperature during carbothermal reduction.

initial mass $\left(m_{\mathrm{o}}\right)$ according to eq. (2).

$$
\alpha=\left(\Delta m / m_{\mathrm{o}}\right) \times 100
$$

The theoretical mass fraction of the reaction (1) was $51.68 \%$ after complete carbothermal conversion of the titanium dioxide by the reaction. The mass fraction of the powder mixtures, in the present study, should have a value of $51.68 \%$ after complete carbothermal conversion of the titanium dioxide powder. As shown in Fig. 2, the values of the mass fraction of the mixtures at a $1673 \mathrm{~K}$ were higher than $51.68 \%$, which means that the present titanium oxide in the mixtures could not be completely converted to titanium carbide during the analysis by TG-DTA. The $\mathrm{TiO}_{2}(\mathrm{I})$ and $\mathrm{TiO}_{2}$ (II) powders which have a mixed phase structure of anatase and rutile structures demonstrated similar carbothermal reduction behavior. These powder mixtures showed a remarkable 


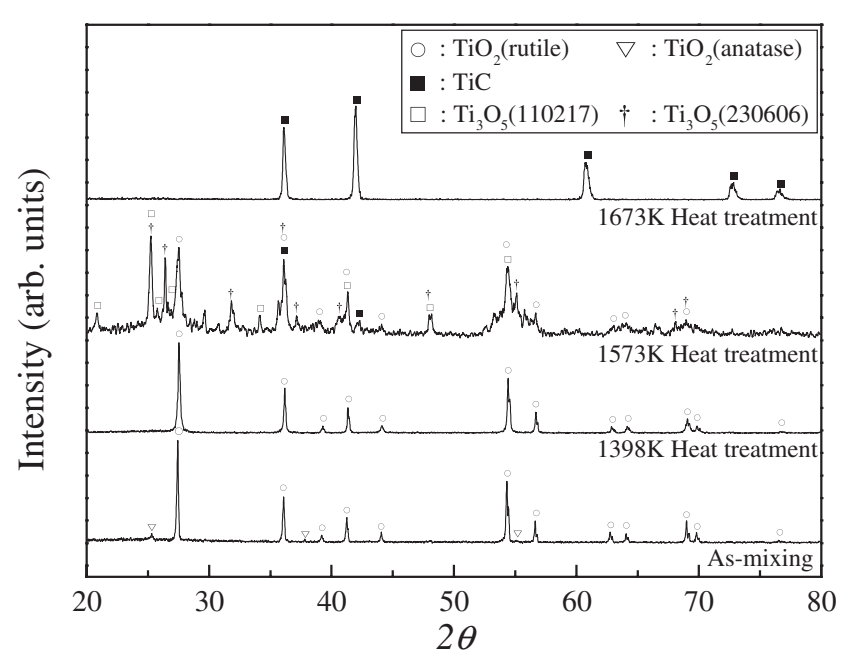

Fig. 3 X-ray diffraction patterns of the mixture of the $\mathrm{TiO}_{2}(\mathrm{I})$ and carbon black heat treated at a specified temperature for 30 minutes.

decrease in the mass fraction at about $1523 \mathrm{~K}$. The $\mathrm{TiO}_{2}(\mathrm{IV})$ powder which has a $100 \%$ anatase phase structure with a mean particle size of $300 \mathrm{~nm}$ showed a remarkable decrease in the mass fraction at about $1473 \mathrm{~K}$. The $\mathrm{TiO}_{2}$ (III) powder which has also a $100 \%$ anatase phase structure with a smaller mean particle size then the value of the $\mathrm{TiO}_{2}(\mathrm{IV})$ powder showed a striking decrease in the mass fraction occurring at about $1373 \mathrm{~K}$. The remarkable decreasing point of the mass fraction on the mass-fraction-temperature diagram in the carbothermal reduction means that the notable carbothermal reaction occurs at this point (or temperature). The $\mathrm{TiO}_{2}$ (III) powder exhibited the lowest notable reaction temperature, about $1373 \mathrm{~K}$, of the carbothermal reduction. The notable reaction temperature increased in the order of $\mathrm{TiO}_{2}$ (III), $\mathrm{TiO}_{2}(\mathrm{IV}), \mathrm{TiO}_{2}$ (II) and $\mathrm{TiO}_{2}(\mathrm{I})$. The carbothermal reduction of the titanium dioxide powder by the carbon black showed very different behavior with the starting titanium dioxide powder.

Figure 3 shows the X-ray diffraction patterns of the mixture of the $\mathrm{TiO}_{2}(\mathrm{I})$ and carbon black heat treated in the tube furnace under a flowing stream of argon at a specified temperature for 30 minutes. The heat-treatment temperature was determined with reference to the change in the mass fraction during carbothermal reduction which is shown in Fig. 2. In the mixing state, the X-ray diffraction pattern shows only $\mathrm{TiO}_{2}$ peaks which have a $95 \%$ rutile phase structure and $5 \%$ anatase phase structure. This diffraction pattern changed to $100 \%$ rutile phase structured $\mathrm{TiO}_{2}$ peaks at $1398 \mathrm{~K}$. The Xray diffraction pattern of the mixed powder heat treated at $1573 \mathrm{~K}$ shows four kinds of phase structure peaks of the rutile- $\mathrm{TiO}_{2}, \mathrm{Ti}_{3} \mathrm{O}_{5}$ (JCPD No. 230606), $\mathrm{Ti}_{3} \mathrm{O}_{5}$ (JCPD No. 110217), and a small amount of TiC. Also, only TiC peaks can be seen in the diffraction pattern of the mixture heat treated at $1673 \mathrm{~K}$. The $\mathrm{TiO}_{2}(\mathrm{I})$ powder which has a $95 \%$ rutile phase structure and $5 \%$ anatase phase structure with an average particle size of $700 \mathrm{~nm}$ had undergone phase transformation from the metastable anatase phase structure to the stable rutile phase structure during heating. The rutile phase structure $\mathrm{TiO}_{2}$ was then carbothermally reduced to TiC by the carbon black. A chemical reaction between titanium

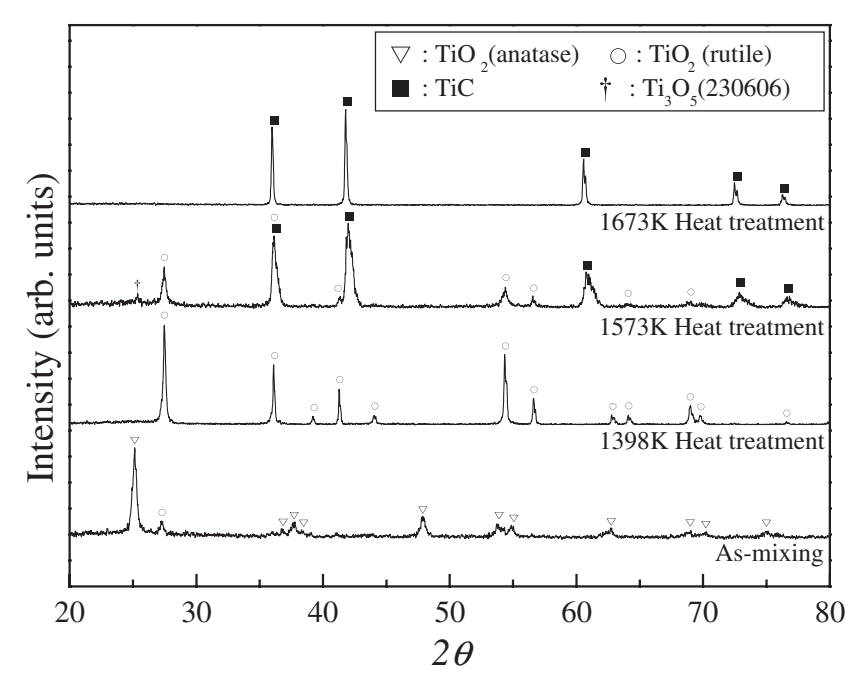

Fig. 4 X-ray diffraction patterns of the mixture of the $\mathrm{TiO}_{2}$ (II) and carbon black heat treated at a specified temperature for 30 minutes.

dioxide and carbon black during the phase transformation of the titanium dioxide could not be found.

Figure 4 shows the X-ray diffraction patterns of reaction products from the $\mathrm{TiO}_{2}$ (II) mixed with carbon black and heat treated at a specified temperature for 30 minutes in the tube furnace under a flowing stream of argon. In the mixing state, the X-ray diffraction pattern exhibits only $\mathrm{TiO}_{2}$ peaks which have a $15 \%$ rutile phase structure and an $85 \%$ anatase phase structure. This diffraction pattern changed to the $100 \%$ rutile phase structured $\mathrm{TiO}_{2}$ peaks at $1398 \mathrm{~K}$. The X-ray diffraction pattern of the mixture heat treated at $1573 \mathrm{~K}$ shows the $\mathrm{TiC}$ phase, and a small amount of the rutile- $\mathrm{TiO}_{2}$ and $\mathrm{Ti}_{3} \mathrm{O}_{5}$ (JCPD No. 230606) phases. Only TiC peaks can be seen in the diffraction pattern of the mixture heat treated at $1673 \mathrm{~K}$. The $\mathrm{TiO}_{2}$ (II) powder which has a $15 \%$ rutile phase structure and an $85 \%$ anatase phase structure with an average particle size of $45 \mathrm{~nm}$ had undergone phase transformation from the anatase phase structure to the rutile phase structure before a carbothermal reduction occurs by the carbon black as in the case of the $\mathrm{TiO}_{2}(\mathrm{I})$ powder.

Figure 5 shows the X-ray diffraction patterns of the mixture of the $\mathrm{TiO}_{2}$ (III) and carbon black heat treated in the tube furnace under a flowing stream of argon at a specified temperature for 30 minutes. In the mixing state, the $\mathrm{X}$-ray diffraction pattern shows only a $100 \%$ anatase phase structured $\mathrm{TiO}_{2}$. At $1453 \mathrm{~K}$, there were four kinds of phases in the heat-treated powder: $\mathrm{Ti}_{3} \mathrm{O}_{5}$ (JCPD No. 230606), TiO, rutile- $\mathrm{TiO}_{2}$ and a small amount of the $\mathrm{TiC}$ phases. The $\mathrm{X}$-ray diffraction pattern of the heat-treated powder at $1573 \mathrm{~K}$ shows the $\mathrm{TiC}$ and a small amount of rutile- $\mathrm{TiO}_{2}$. Only $\mathrm{TiC}$ peaks can be seen at $1673 \mathrm{~K}$. In the case of the $\mathrm{TiO}_{2}$ (III) powder which has a $100 \%$ anatase phase structure with an average particle size of $30 \mathrm{~nm}$, the phase transformation from the anatase phase structure to the rutile phase structure simultaneously occurred with carbothermal reduction by the carbon black.

Figure 6 shows the X-ray diffraction patterns of reaction products from the $\mathrm{TiO}_{2}$ (IV) mixed with carbon black and heat treated at a specified temperature for 30 minutes in the tube furnace under a flowing stream of argon. In the mixing 


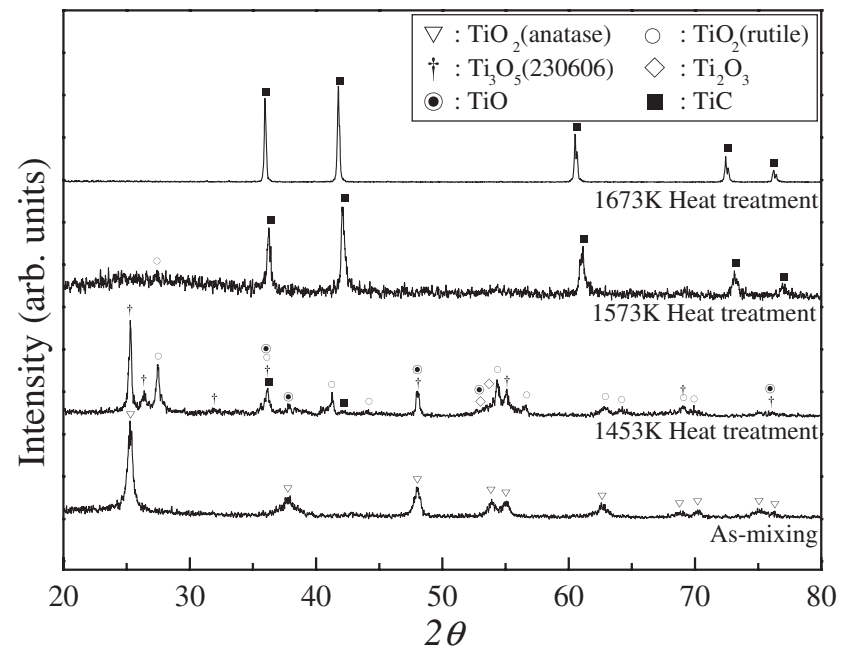

Fig. 5 X-ray diffraction patterns of the mixture of the $\mathrm{TiO}_{2}$ (III) and carbon black heat treated at a specified temperature for 30 minutes.

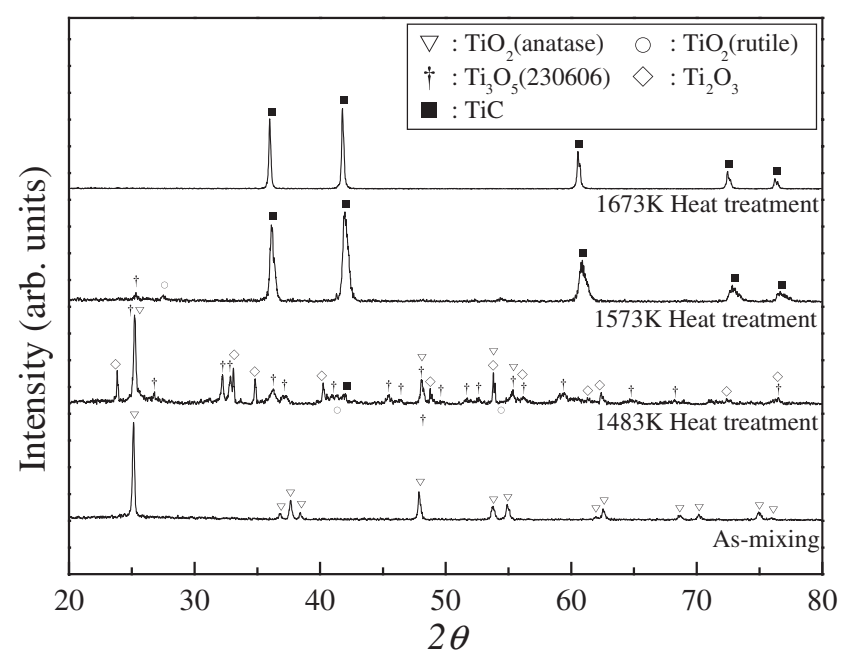

Fig. 6 X-ray diffraction patterns of the mixture of the $\mathrm{TiO}_{2}(\mathrm{IV})$ and carbon black heat treated at a specified temperature for 30 minutes.

state, the $\mathrm{TiO}_{2}$ powder has a $100 \%$ anatase phase structure. The X-ray diffraction pattern of the mixture heat treated at $1483 \mathrm{~K}$ shows the peaks of the $\mathrm{Ti}_{3} \mathrm{O}_{5}$ (JCPD No. 230606), $\mathrm{Ti}_{2} \mathrm{O}_{3}$, and small amount of anatase- $\mathrm{TiO}_{2}$ and $\mathrm{TiC}$ phases. At $1573 \mathrm{~K}$, there were $\mathrm{TiC}, \mathrm{Ti}_{3} \mathrm{O}_{5}$ (JCPD No. 230606) and rutile- $\mathrm{TiO}_{2}$ peaks in the $\mathrm{X}$-ray diffraction pattern. Only TiC peaks can be observed in the diffraction pattern of the mixture heat treated at $1673 \mathrm{~K}$. The $\mathrm{TiO}_{2}(\mathrm{IV})$ powder which has a $100 \%$ anatase phase structure with an average particle size of $300 \mathrm{~nm}$ had phase transformation occur simultaneously with carbothermal reduction as in the case of the $\mathrm{TiO}_{2}$ (III) powder. This behavior of the phase transformation and chemical reaction was very different compared to the behaviors of the $\mathrm{TiO}_{2}$ (I) and $\mathrm{TiO}_{2}$ (II) powders.

The reaction behavior of the carbothermal reduction of the titanium dioxide by the carbon black was very different depending on the characteristics of the starting titanium dioxide. The characteristics of the phase transformation, especially, were very different with the phase structure of the

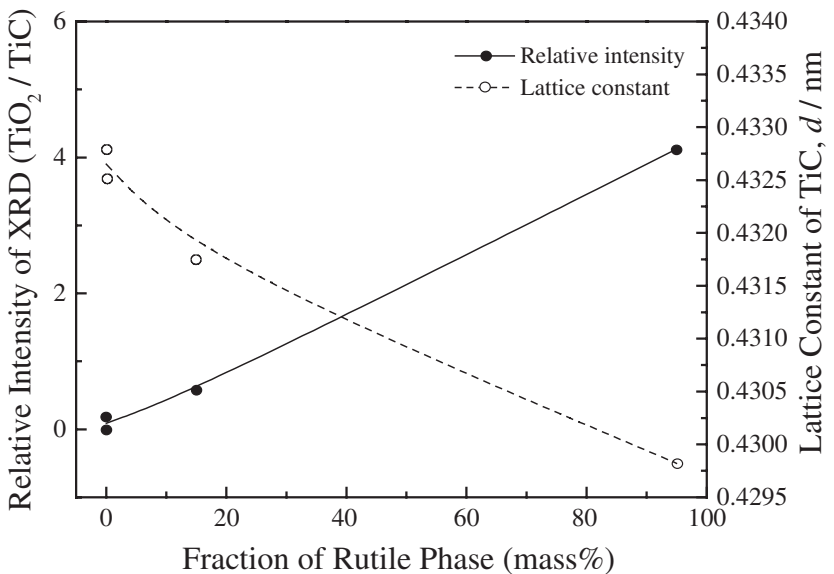

Fig. 7 Changes in the relative intensity of the XRD peaks of the titanium oxide to $\mathrm{TiC}$, and lattice constant of the $\mathrm{TiC}$ with the fraction of the rutile phase in the starting titanium dioxide.

titanium dioxide. The titanium dioxide with the mixed-phase structure of the rutile and anatase phases, $\mathrm{TiO}_{2}(\mathrm{I})$ and $\mathrm{TiO}_{2}(\mathrm{II})$, had a full phase transformation from the metastable anatase phase structure to the stable rutile phase structure before a chemical reaction occurred between the titanium dioxide and carbon. The titanium dioxide with a $100 \%$ anatase structure, $\mathrm{TiO}_{2}$ (III) and $\mathrm{TiO}_{2}(\mathrm{IV})$, however, had a chemical reaction occur between titanium dioxide and carbon black before the final phase transformation. In general, the phase transformation and the chemical reaction were accompanied by the diffusion of atoms (or migration of atoms). The correlation between the phase transformation and chemical reaction was very important in the case of the chemical reaction accompanied by the phase transformation of the raw materials.

Figure 7 shows the changes in the relative intensity of the XRD peaks of the titanium oxide to $\mathrm{TiC}$, and the lattice constant of the $\mathrm{TiC}$ with the fraction of the rutile phase in the starting titanium dioxide. The relative intensity of the XRD peaks of the titanium oxide to $\mathrm{TiC}$ indicate the ratio of the rutile- $\mathrm{TiO}_{2}$ to $\mathrm{TiC}$ of the XRD peaks of the powder mixture heat treated at $1573 \mathrm{~K}$ for 30 minutes in the tube furnace. The peak intensities for the rutile- $\mathrm{TiO}_{2}$ and $\mathrm{TiC}$ correspond to the (110) and (200), respectively. The theoretical lattice constant of the TiC was $0.43274 \mathrm{~nm} .{ }^{10)}$ The relative intensity of the XRD peaks of the titanium oxide to $\mathrm{TiC}$ means the relative amount of the retained titanium oxide in the carbothermally reduced mixture powder. As shown in Fig. 7, the amount of the retained titanium oxide was increased with increasing fraction of the rutile phase in the starting titanium dioxide. Also the lattice constant of the formed TiC decreased with increasing fraction of the rutile phase in the starting titanium dioxide. This means that the $\mathrm{TiC}$ formation ability of titanium dioxide by the carbon black decreased with increasing fraction of the rutile phase in the starting titanium dioxide.

Figure 8 shows the changes in the relative intensity of the XRD peaks of the titanium oxide to $\mathrm{TiC}$, and the lattice constant of the $\mathrm{TiC}$ with the mean particle size of the starting titanium dioxide powder. The relative intensity of the XRD peaks of the titanium oxide to TiC did not vary much in the 


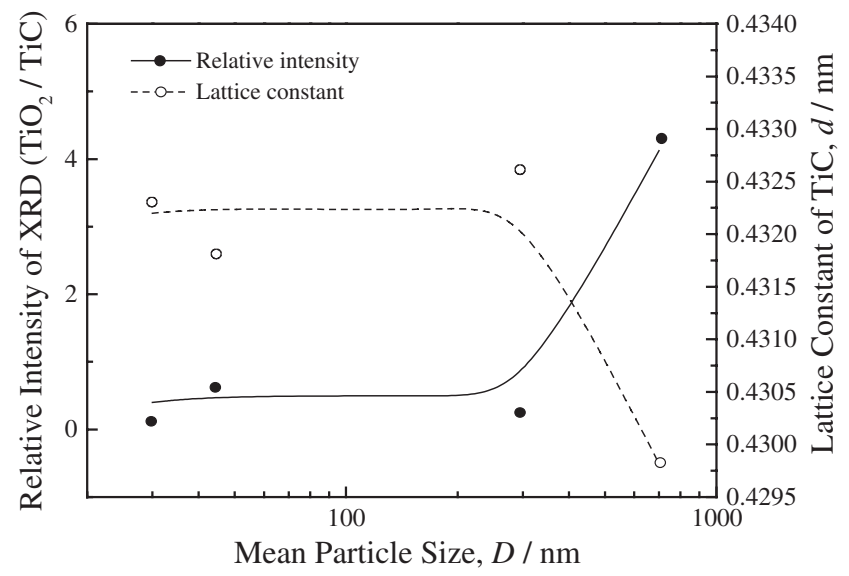

Fig. 8 Changes in the relative intensity of the XRD peaks of the titanium oxide to $\mathrm{TiC}$, and lattice constant of the $\mathrm{TiC}$ with a mean particle size of the starting titanium dioxide.

particle size range from $30 \mathrm{~nm}$ to $300 \mathrm{~nm}$ and drastically increased when above $300 \mathrm{~nm}$. The lattice constant of the TiC decreased with increasing average particle size of the starting titanium dioxide as with the change in the relative intensity with the particle size. This means that the $\mathrm{TiC}$ formation ability decreased with the increasing particle size of the starting titanium dioxide. However, the behavior of the $\mathrm{TiO}_{2}$ (IV) powder which has an average particle size of $300 \mathrm{~nm}$ becomes the object of our attention. This powder has a larger particle size of about ten times the value of the nanoscale-sized powders, $\mathrm{TiO}_{2}$ (II) and $\mathrm{TiO}_{2}$ (III). As shown in Fig. 8, the difference between the value of the relative intensity of the $\mathrm{TiO}_{2}$ (IV) powder and the values of the nanoscaled powders was very small, in spite of the large difference of the particle size. The lattice constant of the TiC of these powders has similar values. This means that the $\mathrm{TiO}_{2}$ (IV) powder has a high TiC formation ability considering its particle size. This high TiC formation ability of the $\mathrm{TiO}_{2}$ (IV) powder comes from the phase structure of the $\mathrm{TiO}_{2}$ (IV) powder which has a $100 \%$ anatase phase structure.

The carbothermal reduction of the titanium dioxide was affected not only by the particle size of the starting one but also its phase structure. As previously mentioned, the chemical reaction in the carbothermal reduction was accompanied by the mutual diffusion of atoms (or migration of atoms) between reactants, titanium dioxide and carbon. The degree of the carbothermal reduction of the titanium dioxide mainly depended on the interface reaction between the titanium dioxide and carbon at their contact area. The degree of carbothermal reduction increased with decreasing particle size of the starting powders, because the contact area increased with a decrease in their size. The reaction depended on the atomic structure of the titanium dioxide. The titanium dioxide with the anatase phase structure has a lower density than the one with the rutile phase structure. ${ }^{12)}$ This means that the atomic packing structure of the anatase-phase-structured titanium dioxide has an atomically more open structure than the rutile-phase-structured one. In general, the atomically open-structured material has a high reactivity compared to the one with the atomically close-packed structure in the same chemical composition condition. Titanium dioxide of the metastable anatase phase structure was transformed to the stable rutile phase structure during heating. ${ }^{13)}$ The phasetransformation temperature of the titanium dioxide depended on the chemical composition, particle size, morphology, among other factors. The mixed-phase-structured titanium dioxides, $\mathrm{TiO}_{2}(\mathrm{I})$ and $\mathrm{TiO}_{2}$ (II), were phase transformed from the mixed phase structure (rutile + anatase) to a $100 \%$ rutile phase structure before starting the reaction of the carbothermal reduction. However, the titanium dioxides of the $100 \%$ anatase phase structure, $\mathrm{TiO}_{2}$ (III) and $\mathrm{TiO}_{2}$ (IV), maintained their atomically open structure until starting the reaction of the carbothermal reduction. Therefore, the titanium dioxides of the $100 \%$ anatase phase structure have a high $\mathrm{TiC}$ formation ability compared to the mixed-phase-structured titanium dioxides, as shown in Fig. 7. It is considered that the carbothermal reaction of the titanium dioxide/carbon system was affected by the particle characteristics of the titanium dioxide, especially its phase structure.

\section{Conclusions}

The present study focused on the role of the particle characteristics of titanium dioxide powder, especially phase structure, in the carbothermal reduction of the titanium dioxide/carbon system. The titanium dioxide powders which have a mixed phase structure of the anatase phase structure and rutile phase structure were phase transformed to the $100 \%$ rutile phase structure before starting the reaction of the carbothermal reduction. However, the titanium dioxide powders of the $100 \%$ anatase phase structure maintained their starting phase structure until a reaction occurred with the carbon. The former powders show a lower TiC formation ability than the latter ones. Also, the particle size of the titanium dioxide powder effected the carbothermal reduction. It demonstrated that the trend of the carbothermal reduction increased with decreasing particle size of the titanium dioxide. However, the $100 \%$ anatase phase structured titanium dioxide with a large particle size showed a higher TiC formation ability than the mixed-phase-structured one with a small particle size. It was concluded that the phase structure of titanium dioxide plays a more important role than particle size in the carbothermal reduction of the titanium dioxide/carbon system.

\section{Acknowledgements}

This research was supported by a grant from the Center for Advanced Materials Processing of the 21st Century Frontier R\&D Program funded by the Ministry of Science and Technology, Republic of Korea.

\section{REFERENCES}

1) K. J. A. Brookes: Word Directory and Handbook of Hardmetals and Hard Materials, 6th ed., (International Carbide Data, Marsh Barton, 1996) pp. 9 20.

2) S. Shimada and M. Kozeki: J. Mater. Sci. 28 (1994) 1869 1876.

3) K. J. A. Brookes: Word Directory and Handbook of Hardmetals and Hard Materials, 6th ed., (International Carbide Data, Marsh Barton, 1996) pp. 95 102.

4) K. Thorne, S. Ting and C. J. Chu: J. Mater. Sci. 27 (1992) 4406 4414. 
5) S. Dunmead, W. Moore and A. Weimer: US Patent No. 53380688, (1993).

6) I. N. Mihailescu, M. 1. De Giorge, C. H. Boulmer-Le Borgne and S. Urdea: J. Appl. Phys. 75 (1994) 5286 5294.

7) S. D. Dunmead, Z. A. Munir and J. B. Holt: J. Mater. Sci. 26 (1991) 2410 2416.

8) L. M. Berger: J. Hard Mater. 3 (1992) 3 10.

9) L. M. Berger: J. Mater. Sci. Lett. 20 (2001) 1845 1848.

10) R. Koc and J. S. Folmer: J. Mater. Sci. 32 (1997) 3101 3111.
11) A. Maitre, D. Tetard and P. Lefort: J. European Ceramic Society 20 (2000) $15 \sim 22$.

12) P. Bose, S. K. Pradhan and S. Sen: Mater. Chem. Phys. 80 (2003) $73 \sim 81$.

13) S. Morooka, A. Kobat and K. Kusakabe: Ceramic Transaction Vol. 22 Ceramic Powder Science IV, edited by S. I. Hirano, G. L. Messing and H. Hausner, (The American Ceramic Society, Inc., Ohio, 1991) pp. $109 \sim 114$. 